\title{
Molecular cytogenetic pilot study on pleomorphic adenomas of salivary glands
}

\author{
JOVANNA THIELKER ${ }^{1}$, ANJA WEISE ${ }^{2}$, MONEEB A.K. OTHMAN ${ }^{2}$, ISABEL M. CARRERIA ${ }^{3,4}$, \\ JOANA B. MELO ${ }^{3,4}$, FERDINAND VON EGGELING ${ }^{1,5}$, ORLANDO GUNTINAS-LICHIUS ${ }^{1}$, \\ MONIKA ZIEGLER ${ }^{2}$ and THOMAS LIEHR ${ }^{2}$ \\ ${ }^{1}$ Department of Otorhinolaryngology; ${ }^{2}$ Institute of Human Genetics, Jena University Hospital, \\ Friedrich Schiller University, D-07747 Jena, Germany; ${ }^{3}$ Cytogenetics and Genomics Laboratory and \\ ${ }^{4}$ The Center of Investigation On Environment Genetics and Oncobiology, Faculty of Medicine, \\ University of Coimbra, Polo Ciências da Saúde, Coimbra 3000-354, Portugal; \\ ${ }^{5}$ Institute of Physical Chemistry, Friedrich Schiller University Jena, D-07743 Jena, Germany
}

Received June 25, 2019; Accepted September 24, 2019

DOI: $10.3892 / \mathrm{ol} .2019 .11198$

\begin{abstract}
Pleomorphic adenomas (PAs) of salivary glands are the most frequent entity of solid parotid tumors. Nonetheless, their genetics is not yet well understood. Thus, the current study characterized 14 PAs using a unique combination of cytogenetic, molecular cytogenetic and/or molecular karyotyping based approaches. The current study applied G-banding based on trypsin treatment and Giemsa-staining in peripheral blood and tumor tissue. Additionally, fluorescence in situ hybridization was performed using whole chromosome painting or centromeric probes. Array-based comparative genomic hybridization was also conducted. In 5 of 14 cases, chromosomal and/or submicroscopic alterations were characterized. Balanced and unbalanced translocations, loss or gain of whole chromosomes and submicroscopic copy number alterations were detected. Furthermore, the first case of a so-called 'jumping translocation' in a PA was reported. The genes twist-related protein 1 and distal-less homeobox 5 were also involved in copy number variations in two PAs. In conclusion, approaches utilized in the current study are highly suited to characterize the genetic constitution of PAs.
\end{abstract}

\section{Introduction}

Pleomorphic adenomas (PAs) account for $45.5 \%$ of primary salivary gland tumors. At the same time, $60-70 \%$ of parotid

Correspondence to: Dr Thomas Liehr, Institute of Human Genetics, Jena University Hospital, Friedrich Schiller University, 1 Am Klinikum, Haus F2, Postfach, D-07747 Jena, Germany E-mail: thomas.liehr@med.uni-jena.de

Key words: molecular cytogenetics, pleomorphic adenoma, copy number variations, molecular karyotyping, jumping translocation tumors are Pas (1). European-wide annual incidence of PAs is 4.2-4.9 per 100,000 inhabitants and year (2). PAs are slowly growing tumors which may remain asymptomatic and unrecognized over years, but they also can reach gigantic sizes and, if left untreated, are going together with dysphagia, dyspnea, great morbidity, or even malignant transformation $(2,3)$. After parotidectomy, $2-3 \%$ of cases show local recurrences, while recurrence rates of up to $25-45 \%$ occurred after tumor enucleation (4). Accordingly, few remaining PA-derived tumor cells obviously are sufficient to form recurrent tumor nodules. Since even small resection margins increase the recurrence risk, the standard procedure for PA resection is meanwhile parotidectomy $(5,6)$.

In addition to the influence of surgical technique on recurrence rates, the subtype of the PAs has an influence on prognosis; e.g. myxoid subtype PAs are more adverse than others (7). Other histopathological features, such as a thin tumor capsule, an incomplete capsule surface, pseudopodia (tumor nodules within the tumor capsule separated by a fibrous layer from the actual tumor) or satellite nodules (tumor nodules separated by healthy glandular tissue or fat from the tumor) also predispose to recurrences after PA resection. Additionally, size of the tumor influences later recurrences: Tumors being initially larger have higher recurrence rates than smaller ones (7-9). Finally, young age at first appearance and female gender also predispose to PA recurrences. As all previously mentioned data is descriptive and provide only statistical data, it is still unclear which genetic or molecular-biological causes are responsible for individual recurrence rates and which pathomechanisms enable individual cells of the PAs to develop recurrences.

Immunohistochemical or molecular genetic studies on expression of various receptors and proteins involved in signal transduction pathways were already performed in PAs. The role of Ki67 as a proliferation marker in recurrences remained hereby unclear (10), while an increased expression of some mucin glycoproteins appeared to be prognostic factors (11). Progesterone receptor but not estrogen receptor expression, 
was increased in recurrent PAs compared to the primary tumors (10). Also discussed as cause of recurrences in PAs is the density and incidence of lymphoid and blood vessels in the tumor itself and its environment (12). More recently, PLAG1 and $H M G A 2$ fusion genes have been the focus of research in PAs. Both in PAs and in their recurrences enhanced PLAGI expression could be detected (13).

Surprisingly, basic cytogenetic and molecular cytogenetic studies in PAs are also scarce. Majority of cytogenetic studies showed normal karyotypes in a certain subset of the tested tumors (14-16); a more recent review even claims $30 \%$ of PAs show a normal karyotype (17). However, involvement of chromosomal breakpoints in $8 \mathrm{q} 12,6 \mathrm{p} 21$ and $12 \mathrm{q} 15$, have been reported, too (18). According to (19) no cytogenetic differences could be found in PAs deriving from minor versus such derived from major salivary glands. Molecular cytogenetics based on fluorescence in situ hybridization (FISH) $(20,21)$ is not that frequently applied for research purposes in PAs as well, while some specific FISH-probes for above mentioned loci are routinely used (22). To the best of our knowledge no molecular karyotyping (array-comparative genomic hybridization $=\mathrm{aCGH}$ ) studies have yet been undertaken for PAs.

Overall, there is still a lack of evidence for causal events of recurrence in PAs. Thus, in this pilot study we used for the first time a combination of cytogenetics, FISH and aCGH to characterize genetic alterations being present in overall 14 PAs.

\section{Materials and methods}

Material. Peripheral blood and primary tumor material were taken with written informed consent from 14 patients with PA of salivary gland beween October 2017 and December 2018 (Table I); only cases were included which were classified and confirmed by histopathology and immunohistochemistry as PAs (data not shown). Cells were either subjected to tissue culture following standard procedures, or frozen at $-20^{\circ} \mathrm{C}$.

Cell culture and cytogenetics. Cells from tumor tissue were disassociated by collagenase treatment. The resulting cell suspension was transferred into in situ culture for 2-3 weeks. After trypsin treatment to remove adherent cells from tissue flasks, chromosomes were prepared as previously reported (23). Peripheral blood was cultured for $72 \mathrm{~h}$ and prepared as well as described before (23). In both cases the resulting so-called 'suspension' (methanol/acetic acid 3:1) was dropped on slides, thus spreading the obtained metaphases using the 'air-drying method' $(23,24)$. G-banding based on trypsin treatment and Giemsa-staining (GTG) was applied to achieve banded chromosomes from primary tumor material as well as peripheral blood lymphocytes of each of the 14 patients. Ten metaphases were analyzed per case and tissue. Karyotypes were described according to ISCN 2016 (25).

Molecular cytogenetics. Fluorescence in situ hybridization (FISH) using all 24 human whole chromosome painting probes in one experiment [homemade M-FISH probe set (26)] was applied in cytogenetic preparations from tumor material of cases 2 and 3. Also, centromeric probe D17Z1 (Abbott/Vysis, Wiesbaden, Germany) was used in case 4 . The FISH-procedures was done as reported in (27).
Ten metaphases were analyzed after M-FISH and 20 metaphases after application of D17Z1.

Molecular karyotyping. Whole genomic DNA was extracted from tumor and blood using commercially available kits. This DNA was applied in two selected cases for array-based comparative genomic hybridization (aCGH, Agilent Human Genome CGH Microarray 180K); the blood-derived DNA was used as individual, case specific control for the tumor-derived DNA. aCGH was done as previously described (28).

\section{Results}

In all 14 studied PA-patients no constitutional chromosomal aberrations were detected after GTG-banding of peripheral blood derived T-lymphocytes. Also in 10/14 PA-derived tumor cells normal karyotypes were observed (Table I).

Aberrations were found as follows using a combination of GTG-banding, molecular cytogenetics and/or aCGH (see also Table I):

Case 1. Banding cytogenetics revealed an apparently balanced reciprocal translocation between chromosomes 11 p11.2 and 12q14.3; according to aCGH the break-events in chromosomes 11 and 12 additionally involved a 107.46 and an $809.68 \mathrm{~kb}$ deletion, respectively.

Case 2. Here GTG-banding and M-FISH identified two potentially related clones being present in this tumor with two different balanced translocations: in common was a breakpoint in $8 \mathrm{q} 21.1$. In $6 / 20$ cells the latter region was fused to $3 q 29$ and in the remainder 14 cells $8 \mathrm{q} 21.1$ was fused to $6 \mathrm{q} 27$. As both locations were (sub-) telomeric this may be considered as a so-called jumping translocation.

Case 3. The complex aberrations being present here only could be resolved after M-FISH (Fig. 1). Besides trisomy 7, also a balanced translocation between an X-chromosome and chromosome 8 and two additional marker chromosomes were observed. The latter turned out to be identical products of an unbalanced translocation between chromosomes 1 and 5 .

Case 4 . Banding cytogenetics detected $3 / 10$ cells with monosomy 17; this finding could be confirmed using a centromeric probe for chromosome 17 and evaluating 20 more metaphases-overall loss of one chromosome 17 was present in $23 \%$ of the tumor cells.

Cases 1 and 12, assessed via molecular karyotyping. In this pilot study, only two cases were studied by aCGH. One with a cytogenetic detectable aberration (case 1) and one with a normal GTG-banding karyotype (case 12). In case 1 a $\sim 0.11$ and $\sim 0.81 \mathrm{Mb}$ deletion in the breakpoint regions $11 \mathrm{p} 11.2$ and $12 \mathrm{q} 14.3$ were found including tumor suppressor genes WIF 1 and MEG3. In case 12 a $0.5 \mathrm{Mb}$ deletion was observed in $16 \mathrm{p} 13.3$ comprising among others also the tumor suppressor gene $S T U B 1$. Besides, in case 1 seven copy number variations (CNVs) between 0.23 and $22.27 \mathrm{~kb}$ in size were detected all apart from that in 7p21.1 were heterozygote losses; and in case 2 seventeen CNVs (four losses and thirteen gains) between 0.07 and $42.13 \mathrm{~kb}$ were seen. In both cases DNA extracted from peripheral blood of the corresponding cases were used as controls in aCGH. Thus, even small CNVs should be meaningful (Tables II and III). According to Table III, in 
Table I. The age, sex and (molecular) cytogenetic and aCGH results are listed together with other diagnoses (if available) of the corresponding 14 patients with pleomorphic adenoma.

\begin{tabular}{|c|c|c|c|c|c|c|}
\hline $\begin{array}{l}\text { Case } \\
\text { number }\end{array}$ & Sex & $\begin{array}{c}\text { Age } \\
\text { (years) }\end{array}$ & $\begin{array}{l}\text { De novol } \\
\text { recurrence }\end{array}$ & (Molecular) Cytogenetics & $\mathrm{aCGH}$ & Other diagnoses \\
\hline 1 & $\mathrm{~F}$ & 37 & De novo & $\begin{array}{l}46, X X, t(11 ; 12) \\
(p 12 ; q 14.3)[10]\end{array}$ & $\begin{array}{c}\text { chr11:37.785. } \\
083-37.892 .542 \\
\text { chr12:65,331,276-66, } \\
\text { 140,959xsee also Tab. } 2\end{array}$ & None \\
\hline 2 & $\mathrm{~F}$ & 61 & De novo & $\begin{array}{c}\text { 46,XX,t( } 3 ; 8)(\mathrm{q} 29 ; \mathrm{q} 21.1) \\
{[6] / 46, \mathrm{XX}, \mathrm{t}(6 ; 8)(\mathrm{q} 27 ; \mathrm{q} 21.1)[14]}\end{array}$ & n.d. & $\begin{array}{l}\text { Raynaud- } \\
\text { syndrome, } \\
\text { SHARP- } \\
\text { syndrome }\end{array}$ \\
\hline 3 & $\mathrm{~F}$ & 59 & De novo & $\begin{array}{c}49, \mathrm{X}, \mathrm{t}(\mathrm{X} ; 8)(\mathrm{p} 11.21 ; \mathrm{q} 12) \\
+\operatorname{der}(5) \mathrm{t}(1 ; 5)(\mathrm{q} 12 ; \mathrm{q} 11.2) \times 2,+7[\mathrm{cp} 20]\end{array}$ & n.d. & $\begin{array}{l}\text { Multiple } \\
\text { Sclerosis }\end{array}$ \\
\hline 4 & $\mathrm{~F}$ & 64 & De novo & $45, X X,-17[7] / 46, X Y[24]$ & n.d. & $\begin{array}{l}\text { Von } \\
\text { Willebrand- } \\
\text { syndrome }\end{array}$ \\
\hline 5 & $\mathrm{~F}$ & 54 & De novo & $46, \mathrm{XX}[\mathrm{cp} 10]$ & n.d. & None \\
\hline 6 & $\mathrm{M}$ & 55 & 1. Recurr. & 46,XY[cp10] & n.d. & None \\
\hline 7 & M & 54 & 6. Recurr. & 46,XY[cp10] & n.d. & None \\
\hline 8 & $\mathrm{~F}$ & 50 & De novo & $46, X X[\mathrm{cp} 10]$ & n.d. & None \\
\hline 9 & $\mathrm{M}$ & 55 & 2. Recurr. & 46,XY[cp10] & n.d. & None \\
\hline 10 & $\mathrm{~F}$ & 52 & De novo & $46, X X[c p 10]$ & n.d. & None \\
\hline 11 & $\mathrm{M}$ & 41 & 4. Recurr. & 46,XY[cp10] & n.d. & None \\
\hline 12 & $\mathrm{~F}$ & 69 & 1. Recurr. & $46, X X[10]$ & See Table II & None \\
\hline 13 & $\mathrm{~F}$ & 65 & 3. Recurr. & $46, X X[10]$ & n.d. & None \\
\hline 14 & $\mathrm{M}$ & 48 & De novo & 46,XY[10] & n.d. & None \\
\hline
\end{tabular}

Abbreviations in karyotype formulas are written according to ISCN 2016 [23]. n.d., not determined; recurr., recurrence (number in front of 'recurr.' represents the number of recurrences); F, female; M, male; aCGH, array-based comparative genomic hybridization.

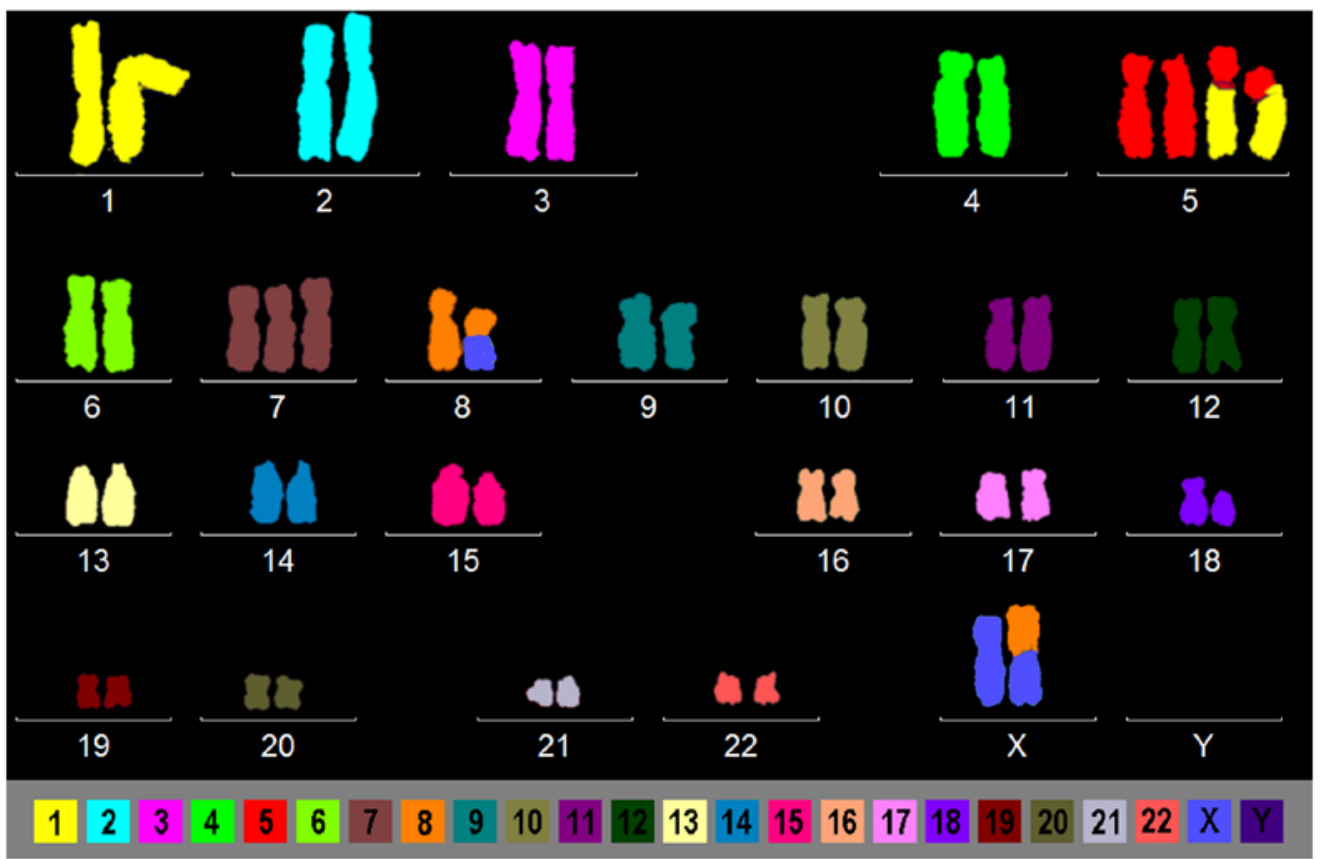

Figure 1. Multiplex fluorescence in situ hybridization results for pleomorphic adenoma tumor cells in case 3 . Two additional derivatives of chromosome $5(+\operatorname{der}(5) \mathrm{t}(1 ; 5)(\mathrm{q} 12 ; \mathrm{q} 11.2) \mathrm{x} 2)$, one additional copy of chromosome 7 (+7) and a reciprocal translocation between the X-chromosome and one chromosome 8 were observed as acquired aberrations. 
Table II. Results of array-based comparative genomic hybridization.

\begin{tabular}{|c|c|c|c|c|}
\hline Case & $\mathrm{Chr}$ & Loss [GRCh37] & Gain [GRCh37] & CNV size $[\mathrm{kb}]$ \\
\hline \multirow[t]{9}{*}{1} & 2 & 2 p23.1(31,806,230-31,807,281) & $7 \mathrm{p} 21.1(19,155,127-19,155,358)$ & 1.05 \\
\hline & 7 & $7 q 21.3(96,651,603-96,655,351)$ & & 0.23 \\
\hline & 11 & $11 \mathrm{p} 15.5(2,015,691-2,020,975)$ & & 3.75 \\
\hline & 12 & $11 \mathrm{p} 12(37,785,083-37,892,542)$ & & 5.28 \\
\hline & 14 & $12 q 14.3(65,331,276-66,140,959)$ & & 107.46 \\
\hline & 17 & $14 q 32.2(101,290,932-101,295,092)$ & & 809.68 \\
\hline & 20 & $17 q 24.3(70,118,098-70,120,417)$ & & 4.16 \\
\hline & & $20 q 11.22(34,006,276-34,028,549)$ & & 2.32 \\
\hline & & & & 22.27 \\
\hline \multirow[t]{17}{*}{12} & 1 & & 1p36.13(16,345,776-16,387,906) & 1.33 \\
\hline & & & 1p31.3(68,516,381-68,517,713) & 0.23 \\
\hline & 2 & 2q31.1(172,964,377-172,964,608) & & 0.21 \\
\hline & 7 & & $7 \mathrm{p} 21.1(19,156,027-19,156,233)$ & 8.51 \\
\hline & & & $7 q 11.23(73,485,261-73,493,768)$ & 2.93 \\
\hline & & & $7 q 21.3(96,652,421-96,655,351)$ & 33.52 \\
\hline & & & $7 q 34(142,453,637-142,487,154)$ & 11.76 \\
\hline & 8 & & $8 p 11.1(43,371,449-43,383,206)$ & 18.54 \\
\hline & & & $8 q 11.1(46,939,154-47,457,692)$ & 1.97 \\
\hline & 11 & & & 0.32 \\
\hline & 15 & $11 \mathrm{p} 15.4(2,904,944-2,906,912)$ & & 0.07 \\
\hline & & $15 q 11.2(23,930,537-23,930,860)$ & $15 q 15.3(43,850,909-43,850,979)$ & 526.88 \\
\hline & 16 & & & 2.51 \\
\hline & 19 & 16 p13.3(433,219-960,098) & $19 q 13.43(57,348,729-57,351,242)$ & 22.02 \\
\hline & 20 & & $20 q 11.22(34,006,276-34,028,297)$ & 1.00 \\
\hline & & & $20 q 11.23(36,150,802-36,151,799)$ & 0.33 \\
\hline & & 20q13.32(57,464,121-57,465,999) & $20 q 13.12(42,184,995-42,185,326)$ & 1.878 \\
\hline
\end{tabular}

Gains and losses were detected in cases 1 and 12 when comparing tumors with blood derived DNA. Chr, chromosome; CNV, copy number variation.

case 1 six out of nine CNVs cover a cancer related gene; in case 12 the rate is about the same: here $15 / 18 \mathrm{CNVs}$ were correlated with tumor related genes in literature. Interestingly in both cases a gain of copy numbers involved the TWIST gene in chromosome 7 p21.1 as well gain or loss, respectively for gene $D L X 5$ in $7 \mathrm{q} 21.3$.

\section{Discussion}

Genetic studies on PAs of salivary gland are scarce. To provide closing this gap, here we provided a yet unique cytogenetic, molecular cytogenetic and molecular karyotyping (aCGH) based pilot approach in 14 PA cases, to learn more about underlying acquired genetic changes in this cancer entity.

First we could confirm that a substantial part of PAs does not harbor any cytogenetically visible alterations. In contrast to the literature we found in GTG-banding normal karyotypes in $4 / 14(\sim 70 \%)$ of our cases and not in only $30 \%$ as previously suggested by others (17). However, this may have to be attributed to small sample size. Also we could, due to financial issues, in this pilot study only test two selected cases by aCGH.
More cryptic unbalanced aberrations may also be present in the other 12 cases.

Additionally we could find several, completely different aberrations in the 4 cases, where cytogenetically visible aberrations were substantiated. As in previous reports, cytogenetically balanced and unbalanced chromosomal rearrangements, as well as numerical aberrations as gains or losses were present (Table I) (14-22). E.g. the loss of chromosome 17 going together with loss of one copy of tumor suppressor gene TP53 has previously been seen in Pas (17).

Besides, this study showed the strengths of the chosen approach, i.e. combining banding cytogenetics with FISH and/or aCGH. Thus, it was easily possible either to better characterize and/or resolve karyotypic changes not to be clarified by GTG-banding alone, like in cases 2 and 3. Similar observations have been made previously for other tumors (29), but not or only rarely for Pas (20). Interestingly in case 2 one of the rare instances of a so-called jumping translocation could be observed; mechanism and meaning for pathology are unclear, still it is the first such observation in a PA (30). 
Table III. Genes involved in the detected CNVs of cases 1 and 12 .

\begin{tabular}{|c|c|c|}
\hline Case & CNVs [GRCh37] & Tumor related genes \\
\hline \multirow[t]{9}{*}{1} & 2p23.1(31,806,230-31,807,281) & n.a. \\
\hline & $7 p 21.1(19,155,127-19,155,358)$ & TSG: TWISTI \\
\hline & $7 q 21.3(96,651,603-96,655,351)$ & ?TSG: DLX5 \\
\hline & $11 \mathrm{p} 15.5(2,015,691-2,020,975)$ & ?OG: $H 19$ \\
\hline & $11 \mathrm{p} 12(37,785,083-37,892,542)$ & n.a. \\
\hline & $12 q 14.3(65,331,276-66,140,959)$ & TSG: WIF 1 \\
\hline & $14 q 32.2(101,290,932-101,295,092)$ & TSG: $M E G 3$ \\
\hline & $17 q 24.3(70,118,098-70,120,417)$ & n.a. \\
\hline & $20 q 11.22(34,006,276-34,028,549)$ & ?OG: $G D F 5$ \\
\hline \multirow[t]{25}{*}{12} & $1 p 36.13(16,345,776-16,387,906)$ & ?TSG: $H S P B 7$ \\
\hline & $1 p 31.3(68,516,381-68,517,713)$ & ?TSG: DIRAS3 \\
\hline & 2q31.1(172,964,377-172,964,608) & ?TSG: $D L X 2$ \\
\hline & $7 p 21.1(19,156,027-19,156,233)$ & TSG: TWIST1 \\
\hline & $7 q 11.23(73,485,261-73,493,768)$ & n.a. \\
\hline & $7 q 21.3(96,652,421-96,655,351)$ & ?TSG: $D L X 5$ \\
\hline & $7 q 34(142,453,637-142,487,154)$ & ?TSG/OG:TCRVB \\
\hline & $8 p 11.1(43,371,449-43,383,206)$ & n.a. \\
\hline & $8 q 11.1(46,939,154-47,457,692)$ & n.a. \\
\hline & $11 \mathrm{p} 15.4(2,904,944-2,906,912)$ & TSG: $C D K N 1 C$ \\
\hline & $15 q 11.2(23,930,537-23,930,860)$ & ?TSG: $N D N$ \\
\hline & $15 q 15.3(43,850,909-43,850,979)$ & ?TSG: PPIP5K1 \\
\hline & $16 \mathrm{p} 13.3(433,219-960,098)$ & ?TSG: PPIP5K1 \\
\hline & & ?TSG/OG: RABIIFIP3 \\
\hline & & ?TSG/OG: $R A B 40 C$ \\
\hline & & TSG: STUB1 \\
\hline & & ?TSG/OG: JMJD8 \\
\hline & & ?TSG/OG: METRN \\
\hline & & ?TSG/OG: $M S L N$ \\
\hline & $19 q 13.43(57,348,729-57,351,242)$ & ?CIN: CHTF18 \\
\hline & $20 q 11.22(34,006,276-34,028,297)$ & ?TSG/OG: PEG3 \\
\hline & $20 q 11.23(36,150,802-36,151,799)$ & ?TSG/OG: GDF5 \\
\hline & $20 q 13.12(42,184,995-42,185,326)$ & TSG: $B L C A P$ \\
\hline & 20q13.32(57,464,121-57,465,999) & OG: $S G K 2$ \\
\hline & & ?TSG/OG: GNAS \\
\hline
\end{tabular}

CNVs detected in cases 1 and 12 by aCGH and the gene located there, which were associated with tumors according to a combined search of UCSC (GRCh37) (genome-euro.ucsc.edu) and pubmed (https://www.ncbi.nlm.nih.gov/pubmed/). Regions present in three copies in the corresponding patient are highlighted in italics and bold letters. CNV, copy number variation; n.a., no tumor related or no gene listed in UCSC; OG, oncogene; TSG, tumor suppressor gene; ?, questionable; CIN, gene correlated with chromosome instability.

Also, cryptic submicroscopic changes could be picked up by applying aCGH in cases 1 and 12. As listed in Table III, in 6/9 to $15 / 18$ of the detected CNVs according to the literature tumor related genes were located. Also TWIST1 and DLX5 genes were involved in CNVs in both by aCGH studied PAs. Thus, here further studies towards the role of these genes in PAs may be indicated.

In conclusion, the setting of pilot study in 14 PAs showed that the combination of banding cytogenetics, FISH and aCGH, maybe in future enlarged by other approaches like MALDI-MS imaging (MSI) (31) enable completely new insights into the genetics of this yet understudied tumor entity. Cryptic and submicroscopic chromosomal aberrations can be picked up more reliably by such an approach.

\section{Acknowledgements}

Not applicable.

\section{Funding}

No funding was received. 


\section{Availability of data and materials}

The datasets used and/or analyzed during the current study are available from the corresponding author on reasonable request.

\section{Authors' contributions}

JT and OGL provided patient material and clinical data. JT, OGL, FVE, AW and TL developed and planned the current study. AW performed cytogenetic analyses and interpretation. MAKO performed DNA-extraction and final aCGH evaluation. MZ conducted the molecular cytogenic experiments. JBM and IMC performed aCGH studies and first evaluation. All authors wrote and approved the final draft of the manuscript.

\section{Ethics approval and consent to participate}

The current study was approved by the Ethical board of the Friedrich Schiller University, medical faculty (approval no. 5241-08/17). Patient consent for participation in the current study was obtained from each participant.

\section{Patient consent for publication}

Not applicable.

\section{Competing interests}

The authors declare that they have no competing interests.

\section{References}

1. Spiro RH: Salivary neoplasms: Overview of a 35-year experience with 2,807 patients. Head Neck Surg 8: 177-184, 1986.

2. Valstar MH, de Ridder M, van den Broek EC, Stuiver MM, van Dijk BAC, van Velthuysen MLF, Balm AJM and Smeele LE: Salivary gland pleomorphic adenoma in the Netherlands: A nationwide observational study of primary tumor incidence, malignant transformation, recurrence, and risk factors for recurrence. Oral Oncol 66: 93-99, 2017.

3. Bist SS, Luthra M, Agrawal V and Shirazi N: Giant parapharyngeal space pleomorphic adenoma causing acute airway obstruction. Oman Med J 32: 240-242, 2017.

4. Witt RL: The significance of the margin in parotid surgery for pleomorphic adenoma. Laryngoscope 112: 2141-2154, 2002.

5. Ghosh S, Panarese A, Bull PD and Lee JA: Marginally excised parotid pleomorphic salivary adenomas: Risk factors for recurrence and management. A 12.5-year mean follow-up study of histologically marginal excisions. Clin Otolaryngol Allied Sci 28: 262-266, 2003.

6. Guntinas-Lichius O, Kick C, Klussmann JP, Jungehuelsing M and Stennert E: Pleomorphic adenoma of the parotid gland: A 13-year experience of consequent management by lateral or total parotidectomy. Eur Arch Otorhinolaryngol 261: 143-146, 2004.

7. Stennert E, Wittekindt C, Klussmann JP, Arnold G and Guntinas-Lichius O: Recurrent pleomorphic adenoma of the parotid gland: A prospective histopathological and immunohistochemical study. Laryngoscope 114: 158-163, 2004.

8. Park GC, Cho KJ, Kang J, Roh JL, Choi SH, Kim SY and Nam SY: Relationship between histopathology of pleomorphic adenoma in the parotid gland and recurrence after superficial parotidectomy. J Surg Oncol 106: 942-946, 2012.

9. Glas AS, Hollema H, Nap RE and Plukker JT: Expression of estrogen receptor, progesterone receptor, and insulin-like growth factor receptor-1 and of MIB-1 in patients with recurrent pleomorphic adenoma of the parotid gland. Cancer 94: 2211-2216, 2002.
10. Hamada T, Matsukita S, Goto M, Kitajima S, Batra SK, Irimura T, Sueyoshi K, Sugihara K and Yonezawa S: Mucin expression in pleomorphic adenoma of salivary gland: A potential role for $\mathrm{MUCl}$ as a marker to predict recurrence. J Clin Pathol 57: 813-821, 2004.

11. Soares AB, de Araújo VC, Juliano PB and Altemani A Angiogenic and lymphangiogenic microvessel density in recurrent pleomorphic adenoma. J Oral Pathol Med 38: 623-629, 2009.

12. Matsuyama A, Hisaoka M, Nagao $Y$ and Hashimoto $H$ : Aberrant PLAG1 expression in pleomorphic adenomas of the salivary gland: A molecular genetic and immunohistochemical study. Virchows Arch 458: 583-592, 2011.

13. de Brito BS, Gaspar NG, Egal ES, Sanchez-Romero C, Martins AS, Tincani ÁJ, de Oliveira Gondak R, de Almeida OP, Kowalski LP, Altemani A and Mariano FV: PLAG1 expression is maintained in recurrent pleomorphic adenoma. Virchows Arch 469: 477-481, 2016

14. Mark J, Dahlenfors R and Ekedahl C: Cytogenetics of the human benign mixed salivary gland tumour. Hereditas 99: 115-129, 1983.

15. Mark J, Dahlenfors R and Wedell B: Impact of the in vitro technique used on the cytogenetic patterns in pleomorphic adenomas. Cancer Genet Cytogenet 95: 9-15, 1997.

16. Craver RD, Fonseca P and Carr R: Pediatric epithelial salivary gland tumors: Spectrum of histologies and cytogenetics at a children's hospital. Pediatr Dev Pathol 13: 348-353, 2010.

17. Ochal-Choińska AJ and Osuch-Wójcikiewicz E: Particular aspects in the cytogenetics and molecular biology of salivary gland tumours-current review of reports. Contemp Oncol (Pozn) 20: 281-286, 2016.

18. Nibert $M$ and Heim S: Uterine leiomyoma cytogenetics. Genes Chromosomes Cancer 2: 3-13, 1990

19. Manor E, Joshua BZ, Brennan PA and Bodner L: Chromosomal aberrations in minor salivary gland pleomorphic adenoma. J Oral Maxillofac Surg 70: 2798-2801, 2012.

20. Alyahya GA, Stenman G, Persson F, Prause JU, Skjødt K, Saunte JP and Heegaard S: Pleomorphic adenoma arising in an accessory lacrimal gland of Wolfring. Ophthalmology 113: 879-882, 2006.

21. Kandasamy J, Smith A, Diaz S, Rose B and O'Brien C: Heterogeneity of PLAG1 gene rearrangements in pleomorphic adenoma. Cancer Genet Cytogenet 177: 1-5, 2007.

22. Sato K, Ueda Y, Shimasaki M, Ozaki M, Nitta N, Chada K, Ishikawa Y and Katsuda S: Pleomorphic adenoma (benign mixed tumor) of the breast: A case report and review of the literature. Pathol Res Pract 201: 333-339, 2005.

23. McGowan-Jordan J, Simons A and Schmid M (eds): ISCN 2016: An International System for Human Cytogenomic Nomenclature. Karger, Basel, pp149, 2016.

24. Weise A and Liehr T: Pre- and postnatal diagnostics and research on peripheral blood, bone marrow chorion, amniocytes, and fibroblasts. In: Fluorescence In Situ Hybridization (FISH)-Application Guide. 2nd edition. Liehr T (ed). Springer, Berlin, pp171-180, 2017.

25. Claussen U, Michel S, Mühlig P, Westermann M, Grummt UW, Kromeyer-Hauschild K and Liehr T: Demystifying chromosome preparation and the implications for the concept of chromosome condensation during mitosis. Cytogenet Genome Res 98: 136-146, 2002.

26. Liehr T and Claussen U: Current developments in human molecular cytogenetic techniques. Curr Mol Med 2: 283-297, 2002.

27. Weise A and Liehr T: Background. In: Fluorescence In Situ Hybridization (FISH)-Application Guide. 2nd edition. Liehr T (ed). Springer, Berlin, pp1-14, 2017.

28. Othman MA, Melo JB, Carreira IM, Rincic M, Glaser A, Grygalewicz B, Gruhn B, Wilhelm K, Rittscher K, Meyer B, et al: High rates of submicroscopic aberrations in karyotypically normal acute lymphoblastic leukemia. Mol Cytogenet 8: 45, 2015.

29. Liehr T, Othman MA and Rittscher K: Multicolor karyotyping and fluorescence in situ hybridization-banding (MCB/mBAND). Methods Mol Biol 1541: 181-187, 2017.

30. Miller CR, Stephens D, Ruppert AS, Racke F, McFaddin A, Breidenbach H, Lin HJ, Waller K, Bannerman T, Jones JA, et al: Jumping translocations, a novel finding in chronic lymphocytic leukaemia. Br J Haematol 170: 200-207, 2015.

31. HoffmannF, Umbreit C,KrügerT,PelzelD,Ernst G, Kniemeyer O, Guntinas-Lichius O, Berndt A and von Eggeling F: Identification of proteomic markers in head and neck cancer using MALDI-MS imaging, LC-MS/MS, and immunohistochemistry. Proteomics Clin Appl 13: e1700173, 2019.

This work is licensed under a Creative Commons Attribution-NonCommercial-NoDerivatives 4.0 International (CC BY-NC-ND 4.0) License. 